\title{
Apontamentos acerca da presença do artista afro-descendente na história da arte brasileira.
}

Francielly Rocha Dossin ${ }^{1}$

RESUMO: O presente artigo pretende dar visibilidade para a presença, comumente silenciada, do artista afro-descendente na história da arte brasileira, entrecruzando leituras e autores que apresentam esses artistas como sujeitos chave na construção da arte brasileira.

PALAVRAS-CHAVE: história da arte, arte brasileira, afro-descendente.

ABSTRACT: This article intends to emphasise the generally silenced presence of afrodescendant artists in brazilian art history, interlacing readings and authors that introduce these artists as key subjects in the brazilian art construction.

KEYWORDS: art history, brazilian art, Afro-descendant.

If you don't understand yourself you don't understand anybody else.

Nikki Giovanni

Este artigo surge a partir do desejo de cartografar a presença de artistas afrodescendentes na historiografia de arte brasileira, menos como forma de mapeamento preciso do que como uma apresentação de determinada postura diante da história da arte, entendendo a participação do homem afro-brasileiro como elemento formador ativo na construção da arte brasileira (ARAÚJO, 1988, p.9). Tal desejo surge exatamente da percepção do silêncio sobre os artistas plásticos afro-descendentes como agente na arte brasileira. É como nos informa Emanuel Araújo,

[...] Não se pode dizer que a vigorosa contribuição do negro à formação de uma cultura legitimamente brasileira não tenha interessado aos nossos estudiosos. Essas pesquisas, todavia, têm praticamente se limitado à escravidão propriamente dita e à herança negra encontrada no sincretismo, na música, no idioma, na literatura e nos costumes. As artes plásticas sempre foram relegadas a plano secundário, limitando-se praticamente a trabalhos isolados e incompletos [...].

${ }^{1}$ Mestranda em Artes Visuais (PPGAV), Centro de Artes (CEART) da Universidade do Estado de Santa Catarina (UDESC), orientada pela prof. ${ }^{a}$ Célia Maria Ramos Antonacci. Integrante do grupo de pesquisa "Poéticas do Urbano" coordenado também pela prof. ${ }^{a}$ Célia Maria Ramos Antonacci. 
As pesquisadoras Silva e Calaça (2006, p. 63) também explicam a profusão de estudos relacionados aos afro-descendentes no Brasil dentro de disciplinas como as ciências sociais e a lacuna do tema em outras áreas como as artes plásticas. Segundo as autoras, "numa revisão bibliográfica dessa produção, fica patente que o número de títulos referentes à arte afro-descendente é diminuto quando comparado com outras áreas do conhecimento, sobretudo com referência às obras que [se] apresentam na linguagem plástica [...]" (ibid., p. 63).

Consequentemente, a mesma negligência acontece em salas de aula ${ }^{\mathrm{i}}$.

Segundo Dilma de Melo e Silva (1997, p. 44), os "livros didáticos de Educação Artística, adotados por $30 \%$ de professores da rede pública e consultados por $70 \%$ destes, são totalmente omissos no que se refere à produção cultural e artística do negro". E continua,

A bibliografia disponível para o ensino da Arte é omissa no que se refere à arte africana e incompleta quanto à afro-brasileira. Os professores de educação artística se formam sem nunca terem tido sequer uma disciplina com conteúdos relativos à estética negra ou às raízes africanas. Tem-se, ainda, em nossa produção simbólica, o agravante da ideologia do embranquecimento e do mito da democracia racial imposta pelos setores hegemônicos da sociedade (ibid., p. 44).

É fato que a historiografia de arte brasileira tem negligenciado esses artistas cuja contribuição é indiscutível. Desta forma continuamos a omitir nossas heranças, a compactuar com o mito do embranquecimento e a perpetuar a imagem perversa que o olhar eurocêntrico destina a África, a seus povos, sua diáspora e seus descendentes.

Verdade também que esta falta tem sido preenchida ou amenizada por diligentes trabalhos desde o final do século XX. A principal obra é certamente "A mão afrobrasileira: significado da contribuição artística e histórica" organizada e prefaciada pelo artista, e hoje diretor do Museu Afro-Brasil, Emanuel Araújo.

Na literatura existente sobre a arte feita por afro-descendentes, há ainda outros importantes pesquisadores, segundo Silva e Calaça (2006, p. 63), constam entre os principais: Alejandro Frigerio, Dilma de Melo Silva, Emanuel Araújo, Marta Heloísa Leuba Salum, Maria Helena Ramos da Silva, Maria Cecília Felix Calaça e Kabengele Munanga. Mesmo não pertencendo exclusivamente à área artística, podemos incluir pesquisadores das ciências humanas e sociais que deram grandes contribuições para o estudo artísticas realizadas por descendentes de africanos, como Roger Bastide, Mariano 
Carneiro da Cunha e George Nelson Preston. Esses autores, principalmente da sociologia e da antropologia, não só deram interessantes contribuições como foram, quiçá, os primeiros a lançar olhar para essas obras que não eram consideradas arte. Um exemplo é o pioneiro ensaio realizado pelo Dr. Nina Rodrigues destinado às artes dos descendentes de escravos que data de 1904, presente também em "A mão afrobrasileira"'ii.

É inegável a existência de expressões artísticas com raízes africanas no Brasil desde o período colonial. Segundo Silva e Calaça (2006, p. 52), “a mão-de-obra escravizada, trazida de várias partes do continente africano a partir de 1535, possuía tradições culturais milenares e tinha o domínio sobre o metal, o bronze, o ferro, o ouro e o marfim". Enquanto que "os colonos portugueses, estavam mais preocupados em desenvolver a empresa açucareira e a procura do ouro".

Sendo a arte entendida como uma atividade manual, consequentemente era uma prática inferiorizada pelos portugueses, pois o bom homem branco era também aquele que nunca tivera de lidar com ofícios vis do qual dependesse seu sustento. Assim sendo esta atividade era predominantemente desempenhada pelos africanos e seus descendentes. Não sem motivo os maiores artistas da época eram afro-descendentes, como Aleijadinho e Mestre Valentim.

Assim sendo, o barroco brasileiro tão pleno de singularidades é fruto principalmente de obras de artistas brasileiros que eram negros ou mulatos ${ }^{\mathrm{iii}} \mathrm{e}$ das confrarias que muitos deles participavam. Como nos recorda Araújo ao citar o pesquisador de música erudita Francisco Curt Lange,

eram as confrarias da gente de cor, berço dos grandes estímulos às manifestações artísticas, ou ainda, que esta gente chegou a impor-se em pouco tempo, graças à sua vida esforçada, sem mácula perante a população dos brancos, ganhando destes admiração, mormente no terreno da música erudita, na escultura, arquitetura e pintura (LANGE apud ARAÚJO, 1988, p. 9).

São do mesmo período as pioneiras e importantes obras da historiografia da arte brasileira, que não coincidentemente dedicam-se a artistas afro-brasileiros. São elas, a obra realizada por Manuel de Araújo Porto Alegre de 1856 sobre a Escola Fluminense de Pintura e outras pesquisas sobre Mestre Valentim, Padre Maurício Nunes Garcia, assim como a monografia de Francisco Bretas sobre o Aleijadinho de 1858, que não deixaram esses artistas caírem no esquecimento (ibid., p. 9). 
Sob a influência da vinda ao Brasil, ainda colônia, da Missão Artística Francesa, seguida do translado da Côrte, cria-se a Academia Imperial de Belas Artes, que no regime republicano passará a se chamar Escola Nacional de Belas Artes. A academia traz os cânones artísticos da Europa e a necessidade de sistematizar nos moldes europeus o ensino e o fazer artístico. Segundo Silva e Calaça (2006, p. 58) "Os 'novos ideais artísticos' afetaram diretamente a produção acadêmica dos artistas negros e seus descendentes".

A academia, segundo as autoras (2006), trouxe obstáculos aos artistas africanos e seus descendentes por motivos diversos, principalmente, sócio-econômicos. Finda as encomendas por parte das confrarias e iniciado um outro sistema, a vinda da Academia não impediu a participação dos artistas afro-brasileiros. Firmino Monteiro, Estevão Silva e Rafael Pinto Bandeira foram os principais representantes dentro da "elitista academia e como tal são o alvo certo para as injustiças do preconceito, levando Pinto Bandeira ao suicídio" (ARAÚJO, 1988, p. 09) e Estevão Silva a reclamar "por não receber a premiação merecida por... discriminação" (AMARAL, 1988, p. 247).

É interessante notar que o artista afro-brasileiro como agenciador artístico esteve muito mais presente na historiografia da arte colonial e imperial. Com a progressiva institucionalização da arte, a inclusão do artista de origem africana tornou-se mais difícil, o que não quer dizer que ele estivesse ausente. A criação da Academia Imperial, não só iniciou esse processo de institucionalização como também de distinção entre belas artes e arte popular/artesanato que se perpetuará nos anos seguintes, como nos explica Amaral já na década de oitenta (1988, p. 247),

Porque o descendente de negro não participa densamente da vida artística brasileira na área de artes plásticas, salvo como primitivo? Pela mesma razão que ele se destaca em esportes que não pressupõem a frequiência a clubes - como atletismo e futebol - e simplesmente estão ausentes dos esportes clubísticos (como iatismo, natação, automobilismo, tênis). E emergem como êxito na música que dispensa, igualmente, uma forma associativa para que sejam descobertos ou projetados.

Feita a distinção, a presença do artista negro estará de modo marcante na arte chamada "popular", ou seja, a arte comumente realizada pelas camadas menos abastadas, feita por artistas que geralmente não tem instrução e ocorre à margem daquilo que a sociedade reconhece como arte: a arte das elites. 
Tentando se desvencilhar dos cânones acadêmicos, temos como marco do modernismo no Brasil a semana de 22, que com caráter nacionalista buscava na cultura brasileira os elementos para a criação de uma arte "nativa". Inspirados pelo ritual antropofágico de índios brasileiros, procuravam no mundo e principalmente no Brasil as inspirações que depois de ingeridas, espoliadas e transformadas seriam a base de uma arte moderna brasileira.

Essa criação passará por um movimento de novas leituras e afirmações acerca dos valores nacionais, direcionando-se a uma "descoberta" da arte popular que influenciou a obra de tantos artistas como Tarsila do Amaral para ficar em apenas um exemplo. Muitos modernistas e artistas considerados populares estabeleceram relacionamentos de trocas intelectuais e artísticas, estimulando uns aos outros. Essa "descoberta" significou também soluções estéticas distantes dos cânones acadêmicos que os artistas modernistas desejavam exceder.

Neste momento o negro passa a ser freqüente nas representações pictóricas, embora muitas vezes ainda de forma estereotipada. Não obstante, o modernismo também possibilitou outras representações do negro, como as proporcionadas pelas missões folclóricas de 1937 e 1938 que colaboraram para dar visibilidade a expressões afro-brasileiras não só religiosas como estéticas. É o que nos explica Munanga (2000, p.72),

a partir das décadas de 30 e 40, a arte afro-brasileira, reduzida ao espaço das casas de culto, começa a sair da clandestinidade. Seus artistas abandonam o anonimato e alguns deles começam a trabalhar dentro do conceito das chamadas arte "popular" e "primitiva", encorajados pelo movimento modernista e pela busca do nacionalismo. Estímulos científicos e culturais tais como os dois congressos afrobrasileiros organizados respectivamente em Recife (1934) e em Salvador (1937), duas missões folclóricas enviadas ao Norte e Nordeste por Mário de Andrade em 1937-38 para coletar material e outros estudos africanistas vão contribuir para o reaparecimento de artistas e temas afro-brasileiros nas artes plásticas.

As autoras Silva e Calaça (2006) aproximam o termo "arte popular" com o termo que elas buscam definir: a "arte afro-descendente", pois segundo elas, a arte popular sendo uma arte que sofre menos influências européias, oferece um lugar privilegiado para manter as expressões ligadas às crenças de origens africanas. As autoras buscam em sua pesquisa a identificação de elementos formais e simbólicos na 
arte brasileira trazida pelos povos africanos a fim de delimitar o que seria uma arte "afro-descendente".

Munanga (2000) também investiga a definição de arte afro-brasileira, para ele, a questão não é semântica, pois inclui diversas questões como a história da escravização, a condição social e político-econômia e também sua cosmovisão. Para o autor, "A questão fundamental que se coloca não é descobrir nas artes plásticas afro-brasileiras os universais da arte em geral, mas sim de defini-la, ou melhor, descrevê-la em relação à arte brasileira de modo generalizado" (MUNANGA, 2000, p. 66). Procurando ver, dessa forma, elementos de africanidade nestas obras, que segundo o autor se dará principalmente na ordem do religioso. Local privilegiado de resistência, instância da vida que resistiu a ruptura da vinda forçada dos africanos ao Brasil (ibid., p. 67-68).

Assim sendo, o conceito de arte afro-brasileira aparece nesses autores como uma forma de delimitar um tipo de arte que preserva elementos estéticos e temáticos oriundos da África, que se deram principalmente na dimensão religiosa.

Despojando aqui do termo "arte afro-brasileira" para lançá-lo a uma exploração futura, é interessante pensarmos o diálogo criado por alguns artistas contemporâneos com as culturas africanas e afro-brasileiras. Como o caso do artista Daniel Lima e Eustáquio neves que vêem desenvolvendo em seus processos plásticos, além de linguagens bastante próprias dentro da arte contemporânea - de forma diversa um do outro - questões sobre a presença do negro na sociedade brasileira.

Estáquio Neves, fotógrafo autodidata, explora questões tais como identidade, corpo e memória pelo viés da denúncia social com encanto e crítica ácida igualmente. Tendo estudado química, ele realiza manipulações que funcionam como estratégias para criação de novos significados e uma estética única, numa tentativa de reorganização do que o circunscreve.

Em sua série "Arturos", realizada entre 1993 e 1996, Neves fotografou a comunidade remanescente de quilombo Arturos em Minas Gerais. Essa série opera não só dentro das questões de memória e identidade, como também "nos convidam a conhecer um mundo que está quase além das diferenças raciais, nos levam a um espaço que nos permite o tempo de nos questionarmos sobre a natureza do mundo espiritual e a complexa relação entre o cristianismo e a diáspora africana" (SEALY, 2005, p. 85).

Eustáquio Neves problematiza também a situação da população negra na sociedade brasileira e a desigualdade social, desde sua série "Caos Urbano" de 1995 à série sobre futebol de 1998. Segundo Sealy (2005, p.86), a posição de Neves é clara, 
ainda não nos reconciliamos com nosso passado colonial. O artista nos convida por meio de sua obra a analisar este passado ainda tão manifesto na sociedade brasileira. Para isso, sua estratégia plástica é tão distante da fotografia documental quando próximo da realidade.

Neves também abarca em sua poética um movimento entre passado e presente e cria uma narrativa fotográfica onde tempo e espaço se diluam, causando muitas vezes certa sensação de imagem em movimento, como na tradição de sociedades africanas, onde as gerações pretéritas além de não esquecidas, são construtoras do presente (HAMPATÉ BA, 1980, passim).

As séries "Boa Aparência" e "Objetização do corpo" podem ser vistas como alegorias calcadas no Real, onde o passado colonial é denunciado como estando fortemente pulsante. Na primeira série, Neves agrupa documentos e artigos de jornais que notificavam fugas de escravos a anúncios de ofertas de emprego que exigem "boa aparência", em uma clara alusão á exclusão dos negros no mercado de trabalho, junto à problemática e "bela" aparência branca (SEALY, 2005, p. 86). O corpo negro continua presente na série "Objetização do corpo", assim como continua presente a "coisificação" e exploração do corpo negro, noções que o fotógrafo interfere e desconstrói, do mesmo modo que interfere e constrói suas imagens. Algumas fotografias das séries citadas constituíram a instalação sonora "Outros Navios" exposta na "Mostra Pan-Africana de Arte Contemporânea". Esse vídeo-instalação demonstra o desenvolvimento da linguagem fotográfica de Neves, que extrapolando a narrativa fotográfica vêem experimentando a linguagem videográfica.

O jovem artista Daniel Lima trabalha desde tecnologias a intervenções urbanas, problematizando aspectos da história e realidade brasileira. Lima também participou da “Mostra Pan-Africana de Arte Contemporânea" realizada em Salvador em 2005, onde apresentou "Coluna Laser III - Mar", constituído em um laser que saía do Solar do Unhão, local da exposição, e se perdia pelo mar, em direção a África. Traz assim uma espécie de ponte por onde perpassam séculos de separação, diáspora, violência e transformações, de forma poética e sutil essa conexão é feita de tal forma intocável ao mesmo tempo em que tangível. O próprio local da Mostra confere ainda mais vigor a essas questões ao lembrar-nos que funcionava como um engenho de açúcar, onde havia casa-grande, capela, pelourinho e senzala.

Lima participa também de coletivos como "A revolução não será televisionada", cujos programas giram em torno do experimentalismo em videoarte e ativismo político 
(ROSAS, 2005, p. 72), e "Frente de 3 de Fevereiro" que nasceu através da mobilização de alguns artistas e pessoas de atividades diversas pelo assassinato do jovem dentista Flávio Sant'Ana em 3 de fevereiro de 2004, confundido com ladrão por policiais. Do coletivo participam diversos artistas e também profissionais como um historiador, um sociólogo e uma advogada. A motivação inicial, o racismo policial, é um dos focos principais das ações do grupo. Esse racismo é transparente pelo termo operacional "suspeito de cor padrão" usado pelos policiais de São Paulo, onde o grupo atua e anuncia que "o sujeito é suspeito por si mesmo. Por ser negro e pobre" (MALAGUTI apud FRENTE 3 DE FEVEREIRO, 2007, p. 26). Dessa forma o grupo problematiza essa constante de diversas maneiras, ações, performances e pesquisas que incluem entrevistas, vídeos e gráficos percentuais.

O grupo une o legado deixado pelos artistas que exploraram o espaço urbano à luta e resistência da cultura afro-brasileira para realizar pesquisas e ações acerca do racismo no Brasil. Remete-nos ao mesmo passado colonial ainda presente na sociedade brasileira e nas questões do fotógrafo Eustáquio Neves. Os dois artistas deixam claro, que apesar de a noção de raça ser uma infeliz ficção biológica, é uma realidade sóciohistórica vivida cotidianamente.

Ainda assim são poucos os artistas afro-brasileiros que emergem no cenário das artes visuais contemporâneas fora do âmbito "popular", como a exemplo de Neves e Lima, principalmente, frente a cada vez maior vinculação da produção artística à produção acadêmica. Como explica Amaral, a razão fundamental é sempre a marginalização sócio-econômica. Pois,

A inexistência de um maior número de artistas plásticos de origem negra é tão real quanto sua ausência nas universidades brasileiras. Dificuldade de acesso, assim como a impossibilidade de viagens, de leituras, de frequiência a um meio mais cultivado, situação que em geral entre nós, continua sendo sempre privilégio de uma pequena camada da população (AMARAL, 1988, p. 247).

Referências:

AMARAL, Aracy. A busca da forma e da expressão na arte contemporânea. In: A mão afro-brasileira : significado da contribuição artística e histórica. São Paulo : Tenenge, 1988. 
ARAÚJO, Emanuel (org.). A mão afro-brasileira : significado da contribuição artística e histórica. São Paulo : Tenenge, 1988.

BENJAMIN, Walter. A obra de arte na era de sua reprodutibilidade técnica. In: Magia e técnica, arte e política : ensaios sobre literatura e história da cultura. São Paulo : Brasiliense, 1994.

FRENTE 3 DE FEVEREIRO, Zumbi somos nós: cartografia do racismo para o jovem urbano. E - book disponível em www.frente3defevereiro.com.br, 2007.

GEERTZ, Clifford. O saber local: novos ensaios em antropologia interpretativa. Petrópolis : Vozes, 2004.

HAMPATÉ BA, Amadou. A tradição viva. In: KI-ZERBO, Joseph (org.). História Geral da África: Metodologia e pré-história da África. V.1. São Paulo: Ática; Paris : UNESCO, 1980.

MUNANGA, Kabengele. Arte afro-brasileira: o que é afinal? In: Mostra do Redescobrimento: arte afro-brasileira = Afro-Brazilian art (Catálogo). São Paulo: Associação Brasil 500 Anos Artes Visuais: Fundação Bienal de São Paulo, 2000. p. 98-111.

ROSAS, Ricardo. Daniel Lima - Lançando um raio de consciência multiplex? Mostra panafricana de arte contemporânea (Catálogo). Salvador - São Paulo: Associação Cultural Videobrasil, 2005.

SEALY, Mark. As fotos de Estáquio Neves. Mostra pan-africana de arte contemporânea (Catálogo). Salvador - São Paulo: Associação Cultural Videobrasil, 2005.

SILVA, Dilma de Melo; CALAÇA, Maria Cecília F. Arte africana e afro-brasileira. São Paulo: Terceira Margem, 2006.

SILVA, Dilma de Melo. Identidade afro-brasileira: abordagem do ensino da arte. In: Comunicação \& Educação - Revista do curso Gestão da Comunicação. Vol. 3, No 10 (1997), acessado em 10/03/2008. Disponível em: http://revcom.portcom.intercom.org.br/index.php/Comedu/issue/view/284 
${ }^{i}$ Com a lei no 10.639, de 9 de janeiro de 2003, que altera a lei $n^{\circ}$ 9.394, de 20 de dezembro de 1996, das diretrizes e Bases da Educação Nacional, e estabelece a obrigatoriedade do ensino de História e Cultura Afro-Brasileira e Africana, poderemos esperar mais pesquisas a respeito da presença do artista afro-descendente.

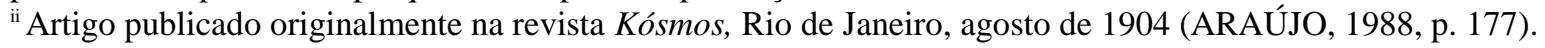

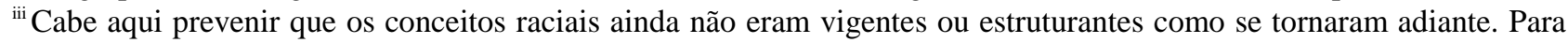
as épocas do Brasil Colonial e Imperial, termos como preto ou negro eram relativos sempre à posição social e não racial. Assim sendo, preto era utilizado para designar o africano, e negro por sua vez, designava o cativo. Esse é também o motivo pelo qual dificilmente encontraremos citações relativas às raças nos escritos e documentos da própria época, mais sim citações em relações a situação social, ascendência ou cor da pele. (notas realizadas durante as aulas da disciplina de História da África I - curso de graduação em História FAED/UDESC - ministrada pelo Prof. Dr. Paulino de Jesus Francisco Cardoso). 